\title{
Gut microbiota composition is associated with body weight, weight gain and biochemical parameters in pregnant women
}

\author{
A. Santacruz ${ }^{1}$, M. C. Collado ${ }^{1}$, L. García-Valdés ${ }^{2}$, M. T. Segura ${ }^{2}$, J. A. Martín-Lagos ${ }^{2}$, T. Anjos ${ }^{2}$, \\ M. Martí-Romero ${ }^{3}$, R. M. Lopez ${ }^{3}$, J. Florido ${ }^{3}$, C. Campoy ${ }^{2}$ and Y. Sanz ${ }^{1 *}$ \\ ${ }^{1}$ Microbial Ecophysiology and Nutrition Group, Institute of Agrochemistry and Food Technology (IATA), Spanish National \\ Research Council (CSIC), Valencia, Spain \\ ${ }^{2}$ Department of Paediatrics, School of Medicine, University of Granada, Granada, Spain \\ ${ }^{3}$ Department of Obstetrics and Gynecology, School of Medicine, University of Granada, Granada, Spain
}

(Received 4 August 2009 - Revised 6 January 2010 - Accepted 11 January 2010 - First published online 8 March 2010)

Obesity is associated with complications during pregnancy and increased health risks in the newborn. The objective of the present study was to establish possible relationships between gut microbiota, body weight, weight gain and biochemical parameters in pregnant women. Fifty pregnant women were classified according to their BMI in normal-weight $(n 34)$ and overweight $(n 16)$ groups. Gut microbiota composition was analysed by quantitative real-time PCR in faeces and biochemical parameters in plasma at 24 weeks of pregnancy. Reduced numbers of Bifidobacterium and Bacteroides and increased numbers of Staphylococcus, Enterobacteriaceae and Escherichia coli were detected in overweight compared with normal-weight pregnant women. E. coli numbers were higher in women with excessive weight gain than in women with normal weight gain during pregnancy, while Bifidobacterium and Akkermansia muciniphila showed an opposite trend. In the whole population, increased total bacteria and Staphylococcus numbers were related to increased plasma cholesterol levels. Increased Bacteroides numbers were related to increased HDL-cholesterol and folic acid levels, and reduced TAG levels. Increased Bifidobacterium numbers were related to increased folic acid levels. Increased Enterobacteriaceae and E. coli numbers were related to increased ferritin and reduced transferrin, while Bifidobacterium levels showed the opposite trend. Therefore, gut microbiota composition is related to body weight, weight gain and metabolic biomarkers during pregnancy, which might be of relevance to the management of the health of women and infants.

Pregnancy: Gut microbiota: Obesity: Cholesterol: TAG: Folic acid: Ferritin

The prevalence of obesity is rapidly increasing worldwide, constituting an important health issue. Obesity is the result of a positive imbalance between energy intake and energy expenditure over a long period and is related to the development of other disorders such as diabetes, dyslipaemia and CVD. Obesity is also associated with complications during pregnancy and at delivery for women and with increased health risks in newborns ${ }^{(1-3)}$.

There are several genetic and environmental factors, such as diet, cultural behaviour and socio-economic status, that influence obesity ${ }^{(4,5)}$. In addition, recent reports suggest that the nature and composition of the intestinal microbiota are altered in obesity ${ }^{(6,7)}$. Lean individuals have more Bacteroidetes, while obese individuals have more Firmicutes, including Clostridium clusters, in their intestinal microbiota ${ }^{(6,7)}$. It has been proposed that such bacterial composition improves the ability of the host to extract energy from the diet and to store this energy in the adipose tissue ${ }^{(7)}$. The gut microbiota has also been related to body weight and body-weight loss under a lifestyle intervention in human subjects ${ }^{(8,9)}$. Although obesity is an important health issue during pregnancy, the relationships between the gut microbiota composition and obesity have been scarcely studied in pregnant women ${ }^{(10)}$.

The aim of the present study was to analyse the microbiota composition of pregnant women and establish its possible relationships with body weight, weight gain and biochemical parameters to progress in the understanding of the role of the microbiota in the health status of pregnant women.

\section{Experimental methods}

\section{Study participants}

The pregnant women were recruited at 20 weeks of pregnancy at the Clinical University Hospital 'San Cecilio' de Granada, Spain. Women were classified according to their pre-pregnancy BMI into two groups: overweight women $(n 16)$ with BMI $>25 \mathrm{~kg} / \mathrm{m}^{2}$ and normal-weight women ( $n$ 34) with BMI $<25 \mathrm{~kg} / \mathrm{m}^{2}$ (Table 1). Signed informed consent was obtained from the studied women after a full explanation of the study had been given by a member of the team at the first visit. Participants were assured of anonymity and confidentiality. After the visit at the first 
Table 1. Clinical characteristics of the studied subjects (Median values and interquartile ranges (IQR))

\begin{tabular}{|c|c|c|c|c|c|}
\hline \multirow[b]{2}{*}{ Characteristics } & \multicolumn{2}{|c|}{$\begin{array}{l}\text { Normal-weight group } \\
\qquad(n 34)\end{array}$} & \multicolumn{2}{|c|}{$\begin{array}{l}\text { Overweight group } \\
\qquad(n 16)\end{array}$} & \multirow[b]{2}{*}{$P^{*}$} \\
\hline & Median & IQR & Median & IQR & \\
\hline \multicolumn{6}{|l|}{ Women } \\
\hline Age (years) & $31 \cdot 0$ & $27 \cdot 7-34 \cdot 2$ & $29 \cdot 0$ & $28.0-33.5$ & 0.646 \\
\hline Height before pregnancy $(\mathrm{cm})$ & $163 \cdot 0$ & $158 \cdot 0-167 \cdot 0$ & $162 \cdot 0$ & $158 \cdot 0-166 \cdot 0$ & 0.967 \\
\hline \multicolumn{6}{|l|}{ Weight $(\mathrm{kg})$} \\
\hline Before pregnancy & $58 \cdot 0$ & $53 \cdot 2-64 \cdot 5$ & $73 \cdot 0$ & $70 \cdot 0-84 \cdot 0$ & $>0.001$ \\
\hline First trimester & 62.5 & $58 \cdot 1-66 \cdot 2$ & $75 \cdot 4$ & $71 \cdot 4-86 \cdot 4$ & $>0.001$ \\
\hline Second trimester ( 24 weeks) & $66 \cdot 4$ & $60 \cdot 7-72 \cdot 3$ & $77 \cdot 3$ & $73 \cdot 5-88 \cdot 6$ & $>0.001$ \\
\hline Third trimester (34 weeks) & $70 \cdot 4$ & $66 \cdot 0-75 \cdot 5$ & $81 \cdot 2$ & $78 \cdot 0-100 \cdot 0$ & $>0.001$ \\
\hline Weight gain over pregnancy $(\mathrm{kg})$ & $11 \cdot 7$ & $8 \cdot 8-14 \cdot 3$ & $10 \cdot 0$ & $6 \cdot 2-11 \cdot 4$ & 0.120 \\
\hline \multicolumn{6}{|l|}{ BMI $\left(\mathrm{kg} / \mathrm{m}^{2}\right)$} \\
\hline Before pregnancy & $23 \cdot 0$ & $20 \cdot 8-24 \cdot 3$ & $28 \cdot 7$ & $26 \cdot 3-31 \cdot 2$ & $>0.001$ \\
\hline First trimester & $23 \cdot 3$ & $21 \cdot 0-25 \cdot 0$ & $29 \cdot 0$ & $27 \cdot 8-32 \cdot 7$ & $>0.001$ \\
\hline Second trimester (24 weeks) & $24 \cdot 0$ & $22 \cdot 7-25 \cdot 7$ & $30 \cdot 0$ & $26 \cdot 8-33 \cdot 2$ & $>0.001$ \\
\hline Third trimester (34 weeks) & $26 \cdot 6$ & $25 \cdot 1-28 \cdot 2$ & $30 \cdot 8$ & $28.9-35.5$ & $>0.001$ \\
\hline \multicolumn{6}{|l|}{ Newborns } \\
\hline Duration of gestation (weeks) & $39 \cdot 0$ & $38.5-40.0$ & 39.5 & $39 \cdot 0-41 \cdot 0$ & 0.165 \\
\hline Birth weight $(\mathrm{kg})$ & $3 \cdot 20$ & $3 \cdot 1-3 \cdot 4$ & 3.50 & $3 \cdot 2-4 \cdot 0$ & 0.028 \\
\hline
\end{tabular}

* Significant differences were calculated using the Mann-Whitney $U$ test. A significant difference between the groups was considered at $P<0.050$.

trimester, women were examined by the obstetrician again at 24 (second trimester) and 34 weeks (third trimester) and clinical parameters were recorded. At 24 weeks of pregnancy, faecal and blood samples were obtained for microbiological and biochemical analysis. Data on weight before pregnancy were used to calculate weight gain during pregnancy. Normal weight gain ranges were from 11.5 to $16.0 \mathrm{~kg}$ for normal-weight women (BMI $19 \cdot 8-25 \cdot 0 \mathrm{~kg} / \mathrm{m}^{2}$ ) and from $7 \cdot 0$ to $11.5 \mathrm{~kg}$ for overweight women (BMI $>25 \mathrm{~kg} / \mathrm{m}^{2}$ ), respectively, over pregnancy according to the Institute of Medicine (IOM) criteria ${ }^{(11)}$. Total weight gains above these values, $>16 \mathrm{~kg}$ for normal-weight women and $>11.5 \mathrm{~kg}$ for overweight women, were considered excessive weight gains. Data on gestation time and birth weights of the newborns were also collected. The present study was conducted according to the guidelines laid down in the Declaration of Helsinki and all procedures involving human subjects were approved by the ethics committee of the Hospital involved in the study. Written informed consent was obtained from all subjects before their inclusion in the study.

\section{Dietary assessment}

Food diary records of pregnant women were kept for $72 \mathrm{~h}$ (two weekdays and one weekend day) at 24 weeks of pregnancy. Detailed information on how to record food and drink consumed using common household measures was provided. Food diary records were returned to each woman's dietitian, and analysed for energy, water and nutrient content based on the CESNID (Centre d'Ensenyament Superior de Nutrició Humana i Dietètica; Centre for Human Nutrition and Dietetics Education) food composition database of Spanish foods ${ }^{(12)}$.

\section{Biochemical parameters}

Fasting plasma glucose, total cholesterol, HDL-cholesterol, TAG, urea, creatinine, uric acid, bilirubin and $\mathrm{Fe}$ were measured by enzyme-colorimetric automated methods for clinical chemistry (Modular Analytics EVO, Roche, Neuilly sur Seine Cedex, France). LDL-cholesterol was calculated using Friedwald's formula ${ }^{(13)}$. Ferritin, transferrin, folate and thyroid-stimulating hormone levels were measured by using the automatic analyser Elecsys 2010 with modular analytics E170 (Roche, Neuilly sur Seine Cedex, France). The transferrin saturation index (TSI) was calculated using the following formula:

$$
\begin{aligned}
\operatorname{TSI}(\%)= & (\text { ferritin }(\mu \mathrm{g} / \mathrm{ml}) \times 100) /(\operatorname{transferrin}(\mathrm{mg} / \mathrm{dl}) \\
& \times 1 \cdot 24) .
\end{aligned}
$$

\section{Sample preparation and DNA extraction}

Faecal samples were frozen immediately at $-20^{\circ} \mathrm{C}$ and kept until processing. Faeces $(1 \mathrm{~g})$ were diluted $1: 10(\mathrm{w} / \mathrm{v})$ in

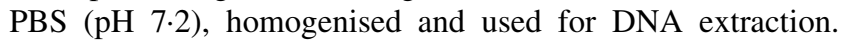
DNA from pure cultures of reference bacterial strains and faecal samples was extracted using the QIAamp DNA stool Mini kit (Qiagen, Hilden, Germany) following the manufacturer's instructions. The concentration of DNA was determined with a Nanodrop-1000 spectrophotometer (Nanodrop, Wilmington, DE, USA).

\section{Analysis of faecal microbiota composition}

Quantitative real-time PCR was used to characterise the microbiota by using specific primers targeting different bacterial groups and the SYBR ${ }^{\circledR}$ Green PCR Master Mix (SuperArray Bioscience Corporation, Frederick, MD, USA), as previously described ${ }^{(9,10)}$. PCR amplification and detection were performed with an ABI PRISM 7000-PCR sequence detection system (Applied Biosystems, Warrington, Ches, UK). Bacterial concentration from each sample was calculated 
by comparing the $\mathrm{C}_{\mathrm{t}}$ (cycle threshold) values obtained from standard curves. Standard curves were created using serial 10-fold dilution of pure culture DNA corresponding to $10^{2}$ to $10^{9}$ cell equivalents/ml (genome equivalents $/ \mathrm{ml}$ ). Conversion of the amount of bacteria DNA in samples determined by quantitative real-time PCR to theoretical genome equivalents required the assumption that the genome size and 16S rRNA gene copy number for each bacterial group analysed were similar. The following genome sizes were used in the study: $2.3 \mathrm{Mb}$ for Bifidobacterium (using Bif. longum as standard); $2.9 \mathrm{Mb}$ for Lactobacillus (L. casei); $5.2 \mathrm{Mb}$ for Bacteroides (Bact. fragilis); $4 \mathrm{Mb}$ for Clostridium coccoides group; $3.3 \mathrm{Mb}$ for $C$. leptum group; $4.6 \mathrm{Mb}$ for Enterobacteriaceae and Escherichia coli; $2.8 \mathrm{Mb}$ for Staphylococcus (Staph. aureus); $2.7 \mathrm{Mb}$ for Akkermansia muciniphila. Genome sizes were obtained from the National Center for Biotechnology Information (NCBI) database (Genome project). Standard curves were created using the following reference strains: Bif. longum subsp. longum CECT 4503; Bact. fragilis DSMZ 2451; C. coccoides DSMZ 933; C. leptum DSMZ 935; Staph. aureus CECT 86; L. casei ATCC 393; E. coli CECT 45; A. muciniphila strain $\operatorname{Muc}^{\mathrm{T}}$ (ATCC BAA-835 ${ }^{\mathrm{T}}$.

\section{Statistical analyses}

Statistical analyses were done using SPSS 11.0 software (SPSS Inc., Chicago, IL, USA). Data distribution was analysed by applying the Kolmogorov-Smirnov test and creating a Gaussian curve. Due to non-normal distribution, microbial data are expressed as medians with interquartile ranges.
The Mann-Whitney $U$ test was applied for comparisons between bacterial numbers of normal-weight and overweight women and between women with excessive and normal weight gain over pregnancy. Differences in prevalence of bacterial groups were established by applying the $\chi^{2}$ test. Correlations between variables were determined by applying the Spearman's rank correlation. $P<0.050$ was considered statistically significant for all tests.

\section{Results}

\section{Body weight, BMI and weight gain over pregnancy}

Clinical characteristics of the studied women at recruitment time were similar in both groups (Table 1) except for BMI and body weight. The body weight of the overweight women was significantly higher than that of normal-weight women during pregnancy, although no significant differences $(P=0 \cdot 120)$ in weight gain were detected between the groups over time. BMI was significantly different $(P<0 \cdot 050)$ between normal-weight and overweight women and increased in both groups over pregnancy. The infants were born at term and the infants' birth weights of the overweight women were higher than those of the normal-weight women $(P=0 \cdot 028)$.

\section{Dietary intakes}

Dietary data of normal-weight and overweight pregnant women at 24 weeks of pregnancy are shown in Table 2. No significant differences in dietary intake of energy, macronutrients or in food group level were found between

Table 2. Daily energy and nutrient intake in normal-weight and overweight women at 24 weeks of pregnancy (Median values and interquartile ranges (IQR))

\begin{tabular}{|c|c|c|c|c|c|}
\hline & \multicolumn{2}{|c|}{$\begin{array}{c}\text { Normal-weight group } \\
\left(18<\mathrm{BMI}<25 \mathrm{~kg} / \mathrm{m}^{2}\right)(n 34)\end{array}$} & \multicolumn{2}{|c|}{$\begin{array}{l}\text { Overweight group } \\
\left(\mathrm{BMI}>25 \mathrm{~kg} / \mathrm{m}^{2}\right)(n 16)\end{array}$} & \multirow[b]{2}{*}{$P^{*}$} \\
\hline & Median & IQR & Median & IQR & \\
\hline Energy (kJ) & 8.86 & $7 \cdot 85-10 \cdot 16$ & 8.06 & $6 \cdot 68-9.74$ & 0.430 \\
\hline Water (g) & $8 \cdot 40$ & $6 \cdot 47-11 \cdot 17$ & 8.02 & $7 \cdot 27-12 \cdot 31$ & 1.000 \\
\hline Protein (g) & $82 \cdot 14$ & $73 \cdot 0-99 \cdot 0$ & $86 \cdot 54$ & $75 \cdot 0-103 \cdot 0$ & 0.610 \\
\hline Protein (\%) & $16 \cdot 31$ & $14 \cdot 7-177$ & $17 \cdot 53$ & $15 \cdot 2-20 \cdot 1$ & 0.265 \\
\hline Plant protein (g) & $25 \cdot 04$ & $22 \cdot 7-28 \cdot 7$ & $23 \cdot 22$ & $16 \cdot 4-26 \cdot 5$ & 0.265 \\
\hline Plant protein (\%) & $4 \cdot 73$ & $4 \cdot 4-7 \cdot 2$ & 4.90 & $3 \cdot 5-5 \cdot 1$ & 0.458 \\
\hline Animal protein $(\mathrm{g})$ & 56.85 & $48 \cdot 3-71 \cdot 7$ & $61 \cdot 25$ & $50 \cdot 6-74.8$ & 0.546 \\
\hline Animal protein (\%) & $11 \cdot 77$ & $9 \cdot 9-12 \cdot 7$ & $13 \cdot 15$ & $10 \cdot 3-15 \cdot 7$ & 0.063 \\
\hline Fat $(g)$ & 91.35 & $75 \cdot 4-105 \cdot 0$ & 85.00 & $62 \cdot 5-105 \cdot 0$ & 0.458 \\
\hline Energy from fat (\%) & $40 \cdot 28$ & $35 \cdot 8-44 \cdot 7$ & $40 \cdot 31$ & $33 \cdot 5-44 \cdot 3$ & 0.926 \\
\hline Saturated fat $(\mathrm{g})$ & $30 \cdot 36$ & $27 \cdot 1-40 \cdot 4$ & $26 \cdot 71$ & $20 \cdot 1-42 \cdot 0$ & 0.577 \\
\hline Energy from saturated fat (\%) & $13 \cdot 77$ & $12 \cdot 2-14 \cdot 9$ & $13 \cdot 33$ & $10 \cdot 0-17 \cdot 6$ & 0.963 \\
\hline MUFA $(g)$ & $37 \cdot 20$ & $30 \cdot 0-48 \cdot 5$ & $34 \cdot 34$ & $27 \cdot 4-41 \cdot 0$ & 0.577 \\
\hline Energy from MUFA (\%) & $16 \cdot 23$ & $14 \cdot 0-20 \cdot 0$ & $16 \cdot 00$ & $15 \cdot 1-17 \cdot 7$ & 0.889 \\
\hline PUFA (g) & $13 \cdot 88$ & $11 \cdot 2-16 \cdot 4$ & $12 \cdot 00$ & $9 \cdot 2-16 \cdot 7$ & 0.458 \\
\hline Energy from PUFA (\%) & 5.6 & $4 \cdot 8-7 \cdot 3$ & 5.56 & $4.4-6.5$ & 0.642 \\
\hline Cholesterol (mg) & $279 \cdot 70$ & $228 \cdot 5-414 \cdot 8$ & $352 \cdot 46$ & $222 \cdot 1-478 \cdot 5$ & 0.458 \\
\hline $\mathrm{CHO}(\mathrm{g})$ & $227 \cdot 70$ & $200-262 \cdot 0$ & $197 \cdot 00$ & $171 \cdot 8-262 \cdot 7$ & 0.330 \\
\hline Energy from $\mathrm{CHO}(\%)$ & 43.06 & $38 \cdot 0-48 \cdot 3$ & $42 \cdot 43$ & $38 \cdot 0-45 \cdot 1$ & 0.610 \\
\hline Simple $\mathrm{CHO}(\mathrm{g})$ & $125 \cdot 20$ & $111 \cdot 8-153 \cdot 3$ & $102 \cdot 12$ & $79 \cdot 0-139 \cdot 5$ & 0.150 \\
\hline Energy from simple $\mathrm{CHO}(\%)$ & $22 \cdot 02$ & $19 \cdot 5-27 \cdot 0$ & $21 \cdot 23$ & $18 \cdot 6-23 \cdot 2$ & 0.280 \\
\hline Complex $\mathrm{CHO}(\mathrm{g})$ & $101 \cdot 51$ & $87 \cdot 5-110 \cdot 8$ & 98.00 & $74 \cdot 8-120 \cdot 2$ & 0.889 \\
\hline Energy from complex $\mathrm{CHO}(\%)$ & $18 \cdot 60$ & $17 \cdot 0-24 \cdot 1$ & $20 \cdot 45$ & $17 \cdot 0-23 \cdot 4$ & 0.816 \\
\hline Dietary fibre $(g)$ & $19 \cdot 81$ & $16 \cdot 2-24 \cdot 3$ & $16 \cdot 75$ & $13 \cdot 6-19 \cdot 0$ & 0.057 \\
\hline
\end{tabular}

$\mathrm{CHO}$, carbohydrates.

* Significant differences were calculated using the Mann-Whitney $U$ test. A significant difference between the groups was considered at $P<0.050$. 
the two groups of women. Only the intake of fibre was slightly higher $(P=0.057)$ in normal-weight than in overweight women. When the women were grouped according to the total weight gain over pregnancy into two groups (excessive and normal weight gain), no significant differences in dietary intake of energy, macronutrients or in food group level were found between the two groups. No correlations were found between dietary intakes, body weight and body-weight gain.

\section{Biochemical parameters}

Biochemical parameters of pregnant women at 24 weeks subdivided according to their BMI into normal-weight and overweight women are shown in Table 3. Bilirubin, Fe and folic acid levels were significantly higher in normal-weight than in overweight women $(P=0.021, P=0.021$ and $P=0.042$, respectively). HDL-cholesterol was higher $(P=0.050)$ in normal-weight than in overweight women, whereas total cholesterol and TAG levels were significantly higher in overweight than in normal-weight women $(P=0.019$ and $P=0.034$, respectively). Moreover, increased levels of TAG $(R 0.30 ; P=0.033)$ and total cholesterol $(R 0.43 ; P=0.002)$ and reduced levels of bilirubin $(R-0.36 ; P=0.019)$ and $\mathrm{Fe}$ ( $R-0.33 ; P=0 \cdot 019)$ correlated with overweight women.

When women were grouped according to the total weight gain over pregnancy into two groups (excessive and normal weight gain), correlations with some biochemical parameters were also detected. Increased levels of total cholesterol $(R 0.33 ; P=0.020)$ and ferritin $(R 0.45, P=0.001)$ correlated with women with excessive weight gain over pregnancy.

\section{Microbiota composition in normal-weight and} overweight women

The bacterial numbers detected in faecal samples of normal-weight and overweight women are shown in Table 4. Bifidobacterium and Bacteroides numbers were significantly higher ( $P>0.001$ and $P=0 \cdot 035$, respectively) in normal-weight women than in overweight women, whereas Enterobacteriaceae $(P=0.001)$, E coli $(P=0.005)$ and Staphylococcus $(P=0.006)$ numbers were lower in normal-weight than in overweight women. C. coccoides group numbers were slightly higher in overweight women than in normal-weight women, but not significantly $(P=0 \cdot 088)$.

The ratio of Bifidobacterium to $C$. coccoides group was significantly higher $(P<0.001)$ in normal-weight than in overweight women. The ratio of Bifidobacterium to both Clostridium groups (C. coccoides plus C. leptum) was also significantly higher $(P<0.001)$ in normal-weight than in overweight women.

Increased numbers of Bifidobacterium $(R-0.56 ; P<0.001)$ and Bacteroides $(R-0.34 ; \quad P=0.020)$ correlated with normal-weight women, while a different trend was found for Staphylococcus $(R \quad 0.67 ; P=0.003)$, Enterobacteriaceae $(R 0.46, P<0.001)$ and $E$. coli $(R 0.40 ; P=0.004)$ (Fig. 1). An increased ratio of Bifidobacterium to $C$. coccoides correlated with lower BMI $(R-0.60 ; P<0.001)$. Similarly, an increased Bifidobacterium to $C$. coccoides plus $C$. leptum ratio was positively related to normal-weight women $(R-0.54 ; P<0 \cdot 001)$.

\section{Microbiota composition according to weight gain over pregnancy}

Faecal microbiota composition of women showing normal or excessive weight gain over pregnancy is shown in Table 5. E. coli numbers were significantly higher $(P=0.045)$ in women with excessive weight gain than in women with normal weight gain over pregnancy. A similar trend was found for Enterobacteriaceae numbers although the differences were not significant $(P=0 \cdot 142)$. Contrary to this tendency, A. muciniphila and Bifidobacterium numbers were higher ( $P=0.020$ and $P=0.078$, respectively) in women with normal weight gain than in those with excessive weight gain.

Table 3. Biochemical parameters recorded at 24 weeks of pregnancy of normal-weight $\left(\mathrm{BMl}<25 \mathrm{~kg} / \mathrm{m}^{2}\right)$ and overweight women $\left(\mathrm{BMl}>25 \mathrm{~kg} / \mathrm{m}^{2}\right)$ (Median values and interquartile ranges (IQR))

\begin{tabular}{|c|c|c|c|c|c|c|}
\hline \multirow[b]{2}{*}{ Biochemical parameter } & \multirow[b]{2}{*}{ Reference value } & \multicolumn{2}{|c|}{ Normal-weight group (n 34) } & \multicolumn{2}{|c|}{ Overweight group ( $n$ 16) } & \multirow[b]{2}{*}{$P^{*}$} \\
\hline & & Median & IQR & Median & IQR & \\
\hline Glucose (mg/l) & $650-1100$ & 765 & $697-810$ & 770 & $635-900$ & 0.840 \\
\hline Urea (mg/l) & $100-500$ & 200 & $175-256$ & 197 & $147-227$ & 0.288 \\
\hline Creatinine (mg/l) & $5-12$ & 6 & $5-7$ & 5 & $5-6$ & 0.072 \\
\hline Uric acid (mg/l) & $24-70$ & 31 & $27-37$ & 33 & $29-37$ & 0.493 \\
\hline Bilirubin $(\mathrm{mg} / \mathrm{l})$ & $0-10$ & 2 & $2-3$ & 1 & $1-3$ & 0.021 \\
\hline Cholesterol (mg/l) & $1200-2200$ & 2330 & $2067-2560$ & 2590 & $2300-2810$ & 0.019 \\
\hline $\mathrm{TAG}(\mathrm{mg} / \mathrm{l})$ & $500-1700$ & 1480 & $1190-1860$ & 1920 & $1630-2250$ & 0.034 \\
\hline HDL-cholesterol (mg/l) & $450-650$ & 770 & 697-955 & 660 & $580-830$ & 0.050 \\
\hline LDL-cholesterol (mg/l) & $500-1500$ & 1350 & $997-1500$ & 1300 & $990-1380$ & 0.580 \\
\hline Total protein $(\mathrm{g} / \mathrm{l})$ & $65-87$ & 70 & $66-71$ & 70 & $67-71$ & 0.502 \\
\hline Albumin $(g / l)$ & $35-50$ & 40 & $37-41$ & 38 & $36-40$ & 0.395 \\
\hline $\mathrm{Fe}(\mu \mathrm{g} / \mathrm{l})$ & $450-1500$ & 795 & $637-1057$ & 600 & $530-950$ & 0.021 \\
\hline Ferritin (ng/ml) & $30-400$ & $19 \cdot 0$ & $10 \cdot 5-31 \cdot 2$ & $20 \cdot 0$ & $16 \cdot 3-33 \cdot 7$ & 0.356 \\
\hline Transferrin $(\mathrm{mg} / \mathrm{l})$ & $2120-3600$ & 3585 & $3207-4130$ & 3500 & $3050-3970$ & 0.288 \\
\hline Saturation transferrin index (\%) & $17 \cdot 1-30 \cdot 6$ & 18.7 & $14 \cdot 0-25 \cdot 0$ & 16.5 & $11 \cdot 6-23 \cdot 0$ & 0.362 \\
\hline Folic acid (ng/ml) & $3 \cdot 1-17 \cdot 5$ & $15 \cdot 3$ & $10 \cdot 6-18 \cdot 5$ & $10 \cdot 5$ & $7 \cdot 3-17 \cdot 0$ & 0.042 \\
\hline $\mathrm{TSH}(\mu \mathrm{UI} / \mathrm{ml})$ & $0.3-4 \cdot 2$ & $1 \cdot 4$ & $0.9-1.7$ & $1 \cdot 6$ & $1.0-1.6$ & 0.368 \\
\hline
\end{tabular}

TSH, thyroid-stimulating hormone.

* Significant differences were calculated using the Mann-Whitney $U$ test. A significant difference between the groups was considered at $P<0.050$. 
Table 4. Bacterial numbers in faecal samples (cell equivalents (genome equivalents) per $g$ faeces) analysed by quantitative real-time PCR at 24 weeks of pregnancy

(Median values and interquartile ranges (IQR))

\begin{tabular}{|c|c|c|c|c|c|c|c|}
\hline \multirow[b]{3}{*}{ Microbial groups } & \multicolumn{3}{|c|}{ Normal-weight women ( $n$ 34) } & \multicolumn{3}{|c|}{ Overweight women ( $n$ 16) } & \multirow[b]{3}{*}{$P^{*}$} \\
\hline & \multirow[b]{2}{*}{ Prevalence } & \multicolumn{2}{|c|}{$\begin{array}{l}\text { Bacterial numbers } \\
\text { (log genome } \\
\text { equivalents/g faeces) }\end{array}$} & \multirow[b]{2}{*}{ Prevalence† } & \multicolumn{2}{|c|}{$\begin{array}{l}\text { Bacterial numbers } \\
\text { (log genome } \\
\text { equivalents/g faeces) }\end{array}$} & \\
\hline & & Median & IQR & & Median & IQR & \\
\hline Total cell counts & $34 / 34$ & 9.85 & $9 \cdot 40-10 \cdot 24$ & $16 / 16$ & 9.89 & $9 \cdot 40-10 \cdot 02$ & 0.630 \\
\hline Bifidobacterium & $34 / 34$ & $9 \cdot 10$ & $8.53-9.52$ & $16 / 16$ & $8 \cdot 36$ & $7.74-8.57$ & $>0.001$ \\
\hline Lactobacillus group & $34 / 34$ & 7.48 & $7.35-7.60$ & $16 / 16$ & $7 \cdot 70$ & $7.40-7.78$ & 0.053 \\
\hline Clostridium coccoides group & $34 / 34$ & 8.52 & $7 \cdot 78-8 \cdot 87$ & $16 / 16$ & $8 \cdot 75$ & $8 \cdot 29-9 \cdot 12$ & 0.088 \\
\hline Clostridium leptum group & $30 / 34$ & $8 \cdot 40$ & $8.04-8.78$ & $14 / 16$ & 8.35 & $7 \cdot 37-8 \cdot 66$ & 0.313 \\
\hline Bacteroides & $34 / 34$ & $6 \cdot 88$ & $6 \cdot 21-7 \cdot 23$ & $16 / 16$ & $6 \cdot 20$ & $6.00-6.66$ & 0.035 \\
\hline Enterobacteriaceae & $34 / 34$ & $6 \cdot 37$ & $6 \cdot 10-6 \cdot 76$ & $16 / 16$ & $7 \cdot 23$ & $6.65-7.90$ & 0.001 \\
\hline Escherichia coli & $34 / 34$ & $5 \cdot 17$ & $4 \cdot 68-5 \cdot 70$ & $16 / 16$ & $6 \cdot 20$ & $5.50-7.14$ & 0.005 \\
\hline Staphylococcus & $8 / 34$ & 4.40 & $3.94-4.74$ & $9 / 16$ & $5 \cdot 78$ & $4 \cdot 83-6 \cdot 37$ & 0.006 \\
\hline Akkermansia muciniphila & $34 / 34$ & 8.35 & $7 \cdot 56-9 \cdot 00$ & $16 / 16$ & 8.50 & $7 \cdot 10-9 \cdot 45$ & 0.763 \\
\hline
\end{tabular}

* Significant differences were calculated using the Mann-Whitney $U$ test. A significant difference between the groups was considered at $P<0.050$

†Prevalence reflects the number of positive amplifications from total samples analysed by PCR ( $n=$ number of samples analysed).

The prevalence of C. leptum group and Staphylococcus was higher in women with excessive weight gain than in women with normal weight gain over pregnancy $(P=0.545$ and $P=0 \cdot 124$, respectively).

Increased numbers of Bifidobacterium $(R-0.31 ; P=0.029)$, Bacteroides $(R-0.36 ; P=0.019)$ and $A$. muciniphila $(R-0.34$; $P=0.017)$ correlated significantly with normal weight gain over pregnancy (Fig. 2). On the contrary, increased numbers of Enterobacteriaceae $(R 0.28 ; P=0.050)$ and $E$. coli $(R 0.42$; $P=0.002)$ correlated with excessive weight gain over pregnancy (Fig. 2).

\section{Relationships between microbiota composition and dietary intakes}

In the whole population of women, only increased numbers of total bacteria correlated with reduced energy $(R-0.71$; $P<0.001)$, animal protein $(R-0.66 ; P=0.001)$, cholesterol $(R-0.57 ; P=0.007)$ and PUFA $(R-0.52 ; P<0.015)$ intakes. The same trend was detected between total bacteria and energy $(R-0.78, P<0.001$ and $R-0.07, P=0.002)$, animal protein $(R-0.61, P<0.015$ and $R-0.75, P=0.001)$ and cholesterol $(R-0.52, P<0.043$ and $R-0.58, P=0.018)$ intakes in the normal-weight group and in the normal weight gain group.

\section{Relationships between microbiota composition and}

\section{biochemical parameters}

In the whole population of women, total bacteria positively correlated with cholesterol $(R \quad 0.350 ; P=0.013)$. Increased numbers of Staphylococcus were related to increased levels of cholesterol ( $R$ 0.68; $P=0.003)$. Increased numbers of Enterobacteriaceae and $E$. coli counts were significantly correlated with increased levels of ferritin $(R 0.324, P=0.023$ and $R \quad 0.425, P=0.002)$ and saturation transferrin index ( $R 0.302, P=0.035$ and $R 0.439, P=0.002)$ and reduced levels of transferrin $(R-0.353, P=0.013$ and $R-0.341, P=0 \cdot 017)$. In contrast, increased numbers of Bifidobacterium were related to reduced levels of ferritin $(R-0.420 ; P=0.003)$ and saturation transferrin index $(R-0.388 ; P=0.006)$ and to increased levels of transferrin $(R 0.348 ; P=0.014)$. In addition, increased numbers of Bifidobacterium were related to increased levels of folic acid $(R 0.308 ; P=0.032)$. Increased numbers of Bacteroides were related to increased levels of HDL-cholesterol $(R 0.518 ; P<0.001)$ and folic acid $(R 0.333$; $P=0.020)$ and to reduced levels of TAG $(R-0.371$; $P=0 \cdot 009$ ).

In normal-weight women, increased numbers of total bacteria correlated with increased levels of cholesterol $(R \quad 0.383$; $P=0.025)$, while in overweight women the correlations were not significant.

In normal weight gain women, increased levels of total bacteria were related to increased levels of total cholesterol ( $R$ 0.390; $P=0.019)$, HDL-cholesterol $(R 0.335 ; P=0.046)$ and folic acid $(R \quad 0.338 ; P=0.044)$. Increased numbers of Staphylococcus correlated with increased levels of total cholesterol $(R 0.881 ; P<0 \cdot 001)$. Moreover, increased numbers of Bacteroides correlated with higher levels of HDLcholesterol $(R 0.620 ; P=0.002)$. In women with excessive weight gain over pregnancy, increased numbers of Bifidobacterium were related to increased levels of HDL-cholesterol $(R \quad 0.572 ; P=0.042)$ and reduced levels of total TAG $(R-0.682 ; P=0.010)$. Increased Bacteroides numbers were related to reduced levels of TAG $(R-0.809 ; P=0.001)$.

\section{Relationships between maternal microbiota composition and infant birth weight}

In the whole population of women, significant positive correlations were found between $E$. coli $(R 0.331 ; P=0.039)$ and $C$. coccoides $(R 0.323 ; P=0.045)$ numbers and infant birth weight. In overweight women, positive correlations were also found between $E$. coli numbers and infant birth weight ( $R$ 0.673; $P=0.035$ ). In excessive weight gain women, significant negative correlations were found between numbers of Lactobacillus group and infant birth weight $(R-0.917$; $P=0 \cdot 001)$. 

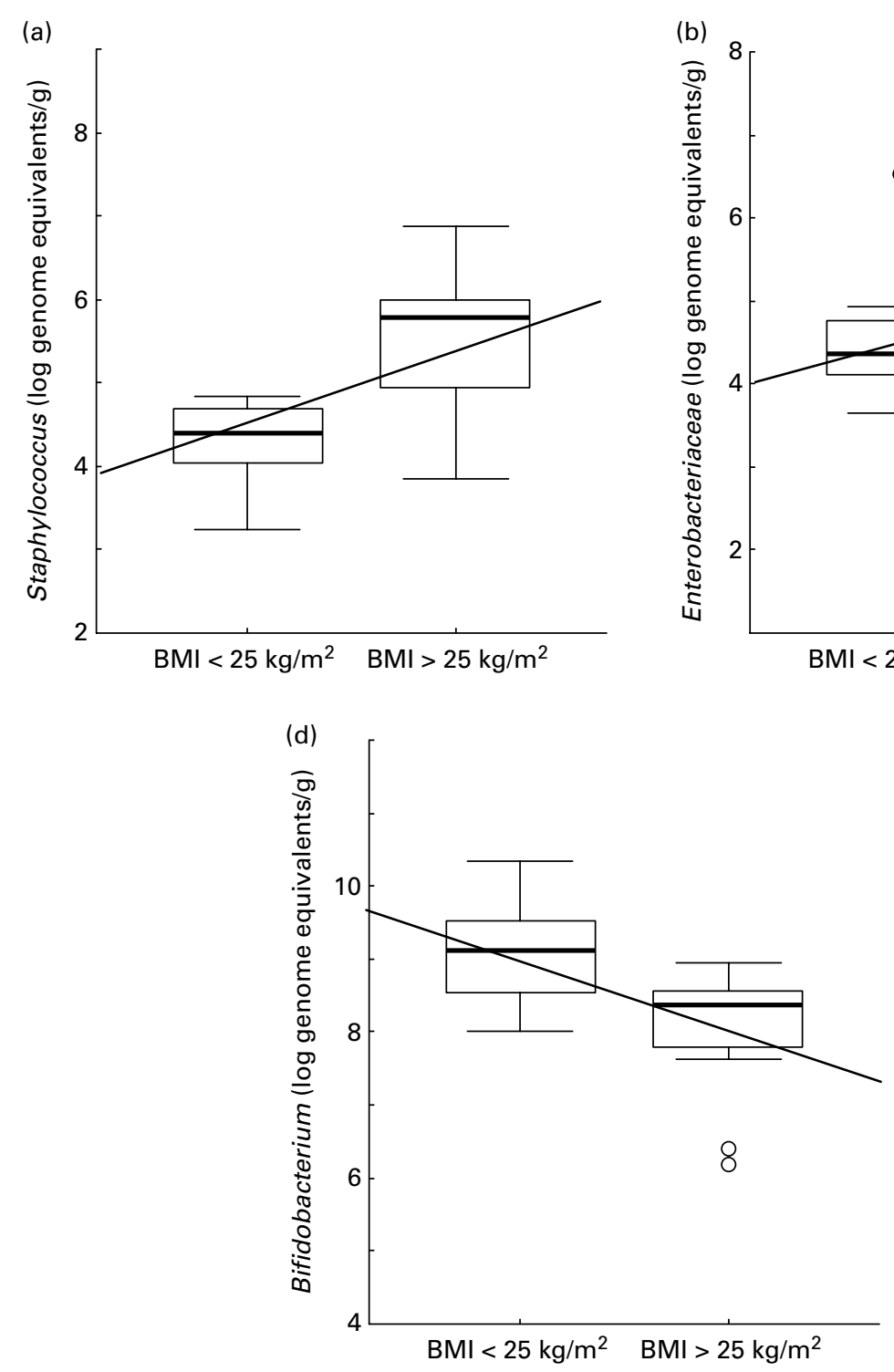
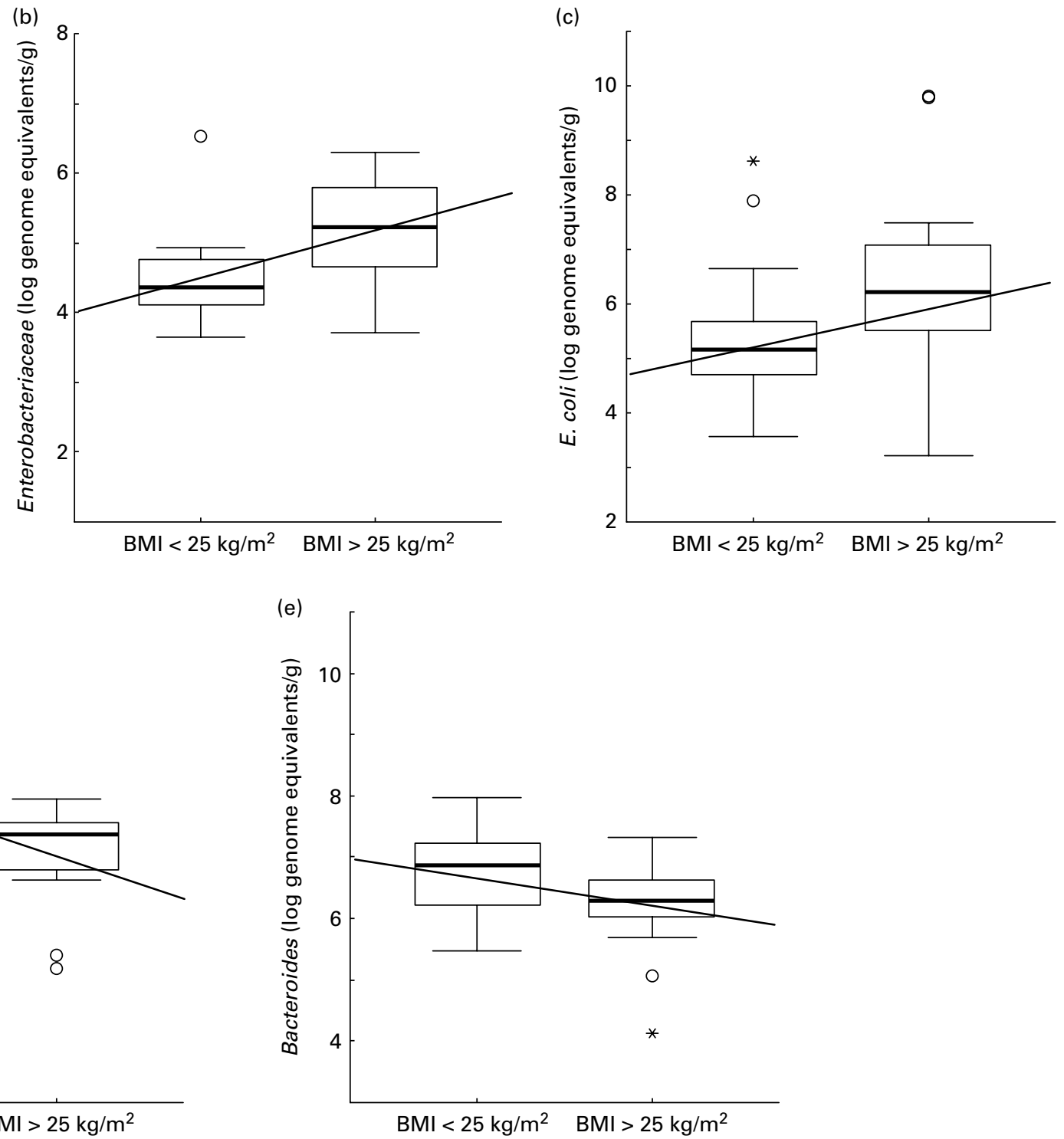

Fig. 1. Relationships between numbers of faecal bacterial groups and weight. Data represent the positive samples. The line in the box is the median (50\% percentile), with the lower line being the lower $25 \%$ border ( $25 \%$ percentile) and the upper line the $75 \%$ ( $75 \%$ percentile) border. The end of the upper vertical line is the maximum data value, outliers not considered. The end of the lower vertical line is the lowest value, outliers not considered. The separate dots or asterisks indicate outliers. Lines show the Spearman correlation (linear adjustment). (a) Staphylococcus ( $R 0.67 ; P=0.003) ;(b)$ Enterobacteriaceae ( $R$ 0.46; $P<0.001$ ); (c) Escherichia coli ( $R$ 0.40; $P=0.004)$; (d) Bifidobacterium ( $R-0.56 ; P<0.001)$; (e) Bacteroides $(R-0.34 ; P=0.020)$. 
Table 5. Bacterial numbers in faecal samples (cell equivalents (genome equivalents) per g faeces) analysed by quantitative real-time PCR according to recommended weight gain over pregnancy

(Median values and interquartile ranges (IQR))

\begin{tabular}{|c|c|c|c|c|c|}
\hline \multirow[b]{3}{*}{ Microbial groups } & \multicolumn{2}{|c|}{ Normal weight gain $(n 36) \dagger$} & \multicolumn{2}{|c|}{ Excessive weight gain ( $n$ 14) } & \multirow[b]{3}{*}{$P^{*}$} \\
\hline & \multirow[b]{2}{*}{ Prevalence } & \multirow{2}{*}{$\begin{array}{c}\begin{array}{c}\text { Bacterial numbers } \\
\text { (log genome } \\
\text { equivalents/g faeces) }\end{array} \\
\text { Median (IQR) }\end{array}$} & \multirow[b]{2}{*}{ Prevalence } & \multirow{2}{*}{$\begin{array}{c}\begin{array}{c}\text { Bacterial numbers } \\
\text { (log genome } \\
\text { equivalents/g faeces) }\end{array} \\
\text { Median (IQR) }\end{array}$} & \\
\hline & & & & & \\
\hline Total cell counts & $36 / 36$ & $9.90(9.51-10.25)$ & $14 / 14$ & $9.73(9.18-10 \cdot 00)$ & $0 \cdot 218$ \\
\hline Bifidobacterium & $36 / 36$ & $8.92(8.27-9.44)$ & $14 / 14$ & $8.46(8.13-8.22)$ & 0.078 \\
\hline Lactobacillus group & $36 / 36$ & $7.48(7.39-7.64)$ & $14 / 14$ & $7.56(7.35-7.76)$ & 0.449 \\
\hline Clostridium coccoides group & $36 / 36$ & $8.71(8.07-8.97)$ & $14 / 14$ & $8.35(8.15-8.67)$ & 0.315 \\
\hline Clostridium leptum group & $32 / 36$ & $8.42(8.16-8.78)$ & $12 / 14$ & $8.17(7.20-8.68)$ & 0.268 \\
\hline Bacteroides & $36 / 36$ & $6.42(6.06-7.03)$ & $14 / 14$ & $6.64(6.20-7.36)$ & 0.331 \\
\hline Enterobacteriaceae & $36 / 36$ & $6.55(6.21-6.86)$ & $14 / 14$ & $6.84(6.16-8.04)$ & 0.142 \\
\hline Escherichia coli & $36 / 36$ & $5.26(4.70-5.94)$ & $14 / 14$ & $6.25(5.06-8.08)$ & 0.045 \\
\hline Staphylococcus & $10 / 36$ & $4.50(4.33-5.74)$ & $7 / 14$ & $4.46(4.08-5.62)$ & 0.527 \\
\hline Akkermansia muciniphila & $36 / 36$ & $8.54(7.90-9.50)$ & $14 / 14$ & $8.12(6.52-8.50)$ & 0.020 \\
\hline
\end{tabular}

* Significant differences were calculated using the Mann-Whitney $U$ test. A significant difference between the groups was considered at $P<0.050$.

$\dagger$ Normal weight gains over pregnancy according to the Institute of Medicine are $<16.0 \mathrm{~kg}\left(\mathrm{BMI}<25 \mathrm{~kg} / \mathrm{m}^{2}\right)$ and $<11.5 \mathrm{~kg}\left(\mathrm{BMI}>25 \mathrm{~kg} / \mathrm{m}^{2}\right)$.

$\ddagger$ Prevalence reflects the number of positive amplifications from total samples analysed by PCR ( $n=$ number of samples analysed).

\section{Discussion}

The present study reports differences in the intestinal microbiota of normal-weight and overweight pregnant women, associated with body weight and weight gain over pregnancy, suggesting that the intestinal microbiota is a relevant target to weight management in pregnancy. Moreover, newborns from overweight pregnant women had higher birth weights than those from normal-weight pregnant women, suggesting the transference of the mother's features to their newborns. In this context, the results can also be of relevance to the transference of the aberrant microbiota to the newborns, which use the maternal microbiota as inoculums for microbiota development ${ }^{(14)}$. In fact, a positive relationship between the maternal intestinal E. coli numbers and infant birth weight was demonstrated, which could be related to infant body weight regulation. In contrast, in women with excessive weight gain, increased Lactobacillus numbers were related to reduced weight gain over pregnancy, suggesting a positive role of this bacterial group in infant body weight regulation.

In the present study, increased numbers of Bacteroides, which belong to the Bacteroidetes phylum, were detected in normal-weight compared with overweight women. In previous studies, the faecal microbiota of lean human subjects was characterised by having increased numbers of Bacteroidetes compared with that of obese subjects. Moreover, weight loss under dietary intervention was associated with increases in Bacteroidetes and Bact. fragilis group numbers in adults and adolescents $^{(6,8,9)}$. Therefore, the association of Bacteroidetes with a lean phenotype established in previous studies has also been confirmed in pregnant women included in the present study. Nevertheless, Bacteroides numbers were significantly higher in overweight than in normal-weight women and associated with excessive weight gain over pregnancy in the only previous study carried out in pregnant women ${ }^{(10)}$. These results contradict all previous findings on the role of Bacteroides in obesity and highlight the importance of the new evidence provided by the present study in this regard.
Increased numbers of Bifidobacterium were also related to normal-weight women compared with overweight women, and a similar trend was detected in women with normal weight gain compared with those with excessive weight gain over pregnancy. This is in agreement with recent studies, which showed that levels of Bifidobacterium were reduced in infants who developed overweight at 7 years old, compared with normal-weight children ${ }^{(14)}$; however, this association was not established in the previous study conducted in pregnant women $^{(10)}$. In animal models, a role has also been attributed to Bifidobacterium in obesity. Obese Zucker rats $(f a l f a)$ and mice fed a high-fat diet showed reduced Bifidobacterium counts ${ }^{(15,16)}$. Moreover, the administration of prebiotics to mice fed a high-fat diet increased the intestinal Bifidobacterium numbers, which positively correlated with improved glucose tolerance and glucose-induced insulin secretion and with the normalisation of the inflammatory tone ${ }^{(16)}$.

In addition, the ratio of Bifidobacterium to either $C$. coccoides or to $C$. coccoides plus $C$. leptum group numbers was also significantly higher in normal-weight than in overweight women, suggesting a negative role of Clostridium in obesity. In agreement, obese human subjects were shown to have increased numbers of Firmicutes in their faecal microbiota as compared with lean subjects ${ }^{(6)}$. Moreover, weight loss under dietary intervention has also been associated with reduction in Firmicutes or $C$. coccoides and $C$. histolyticum group proportions ${ }^{(6,8,9)}$. Altogether, these results confirm that increases in the relative abundance of members of Firmicutes and, in particular, of some Clostridium clusters is associated with excessive body weight.

Staphylococcus numbers were also increased in overweight compared with normal-weight women in agreement with a previous study conducted in pregnant women ${ }^{(10)}$. Moreover, children becoming overweight at 7 years old showed a greater number of Staph. aureus in faeces during infancy ${ }^{(14)}$. In addition, Enterobacteriaceae and E. coli were significantly higher in overweight than in normal-weight women and also in women with excessive weight gain over pregnancy. 
(a)

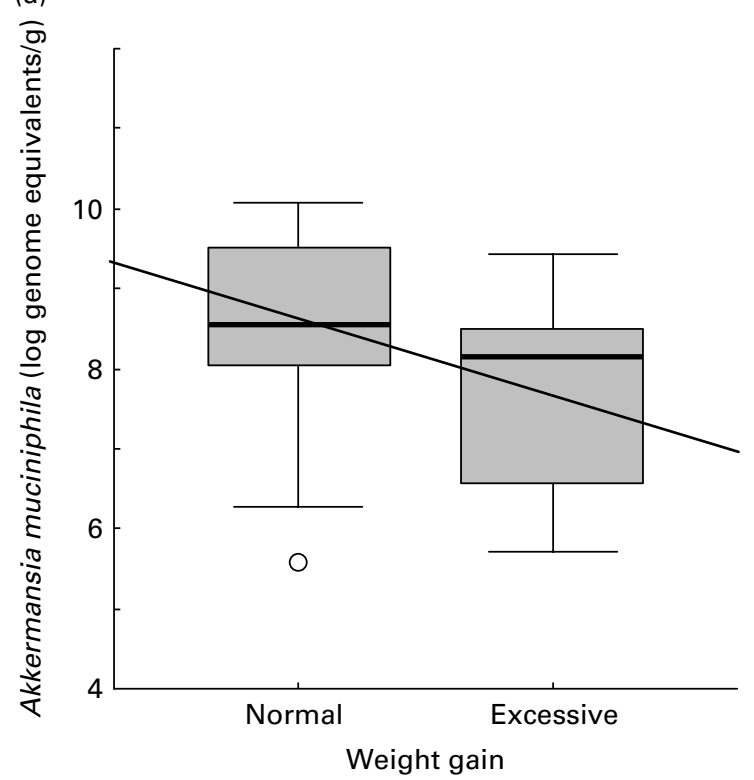

(c)

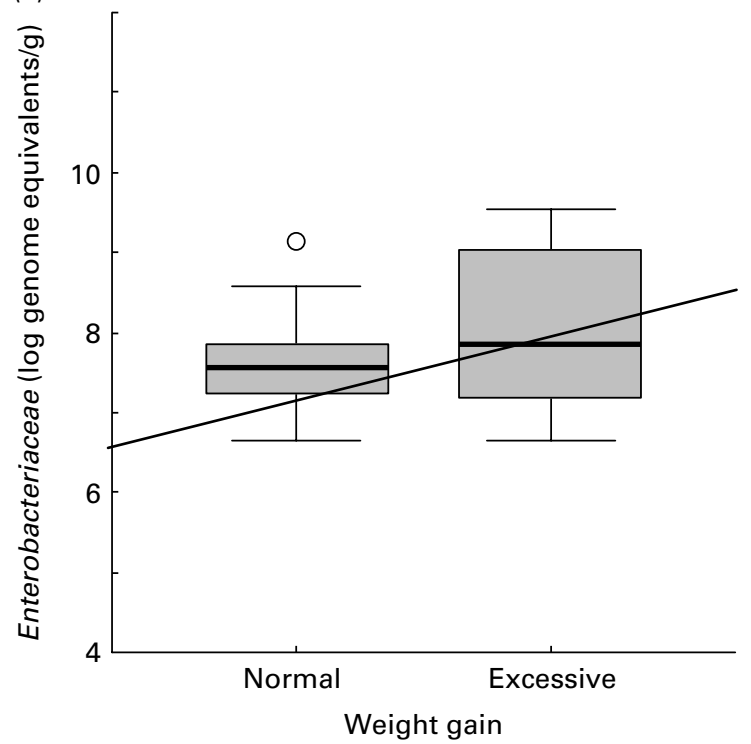

(b)

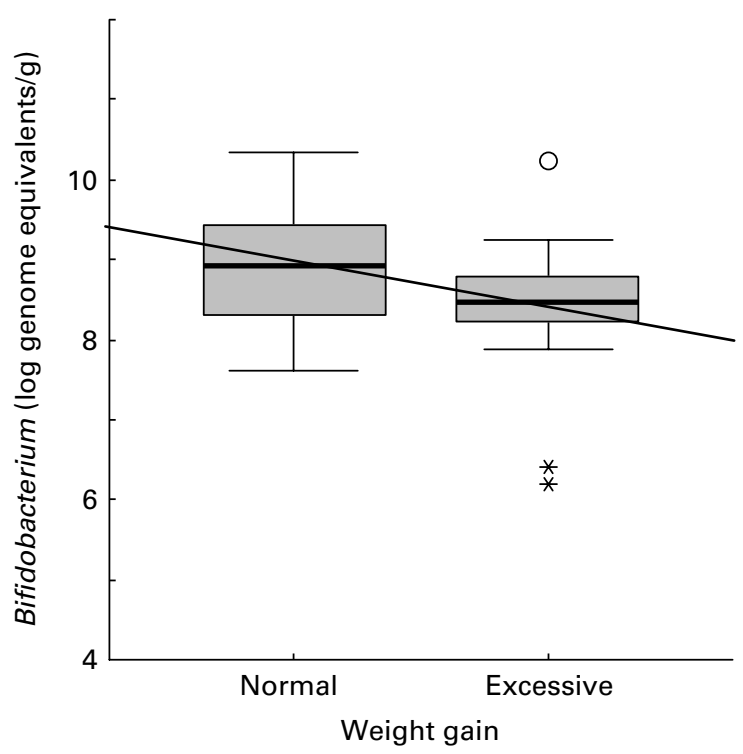

(d)

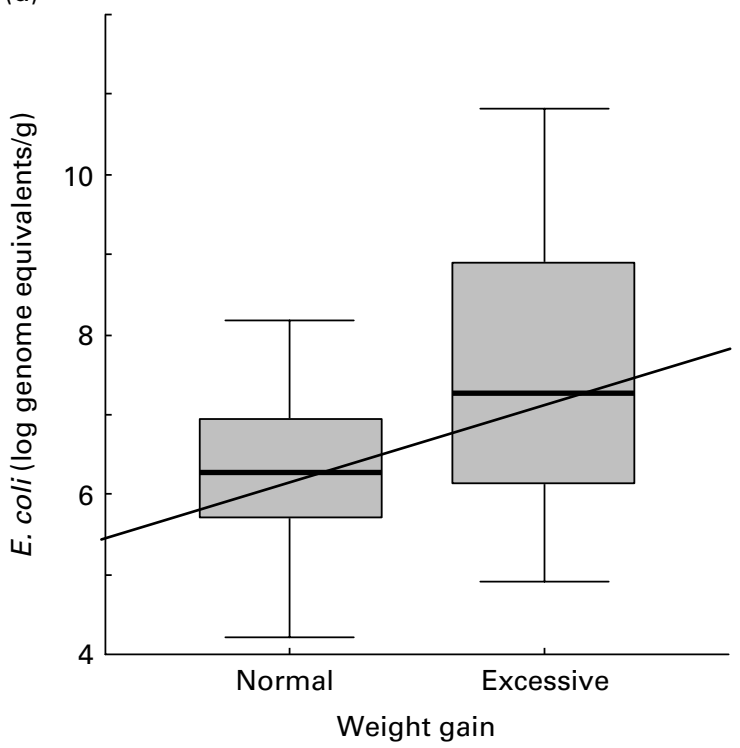

Fig. 2. Relationships between numbers of faecal bacterial groups and weight gain over pregnancy. Data represent the positive samples. The line in the box is the median ( $50 \%$ percentile), with the lower line being the lower $25 \%$ border $(25 \%$ percentile) and the upper line the $75 \%$ ( $75 \%$ percentile) border. The end of the upper vertical line is the maximum data value, outliers not considered. The end of the lower vertical line is the lowest value, outliers not considered. The separate dots or asterisks indicate outliers. Lines show the Spearman correlation (linear adjustment). (a) Akkermansia muciniphila $(R-0.34 ; P=0.017) ;(b)$ Bifidobacterium $(R-0.31 ; P=0.029)$; (c) Enterobacteriaceae $(R 0.28 ; P=0.050)$; (d) Escherichia coli $(R 0.42 ; P=0.002)$.

Increased levels of Gram-negative bacteria, which could include Enterobacteriaceae and E. coli, could be related to the endotoxaemia and inflammatory tone associated with obesity as evidenced in animal models ${ }^{(16)}$.

Total cholesterol and TAG levels were significantly higher in overweight than in normal-weight women and increased cholesterol levels correlated with excessive weight gain over pregnancy, as expected. In addition, folic acid, which is a nutrient involved in the correct differentiation of the neural tube during fetal organogenesis, was significantly lower in overweight than in normal-weight women. In fact, obesity is a risk factor for neural tube defects ${ }^{(17)}$. Moreover,
Fe levels were also lower in overweight than in normalweight women and increased levels of ferritin correlated with higher weight gain in the whole population and in the excessive weight gain group. A relationship has been described between obesity and Fe deficiency, which can be reflected in reduced plasma levels of $\mathrm{Fe}$ and transferrin and increased plasma levels of ferritin and saturation transferrin index ${ }^{(18-22)}$. The Fe deficiency associated with obesity has a multifactorial aetiology and could be due to impairment of intestinal $\mathrm{Fe}$ uptake and $\mathrm{Fe}$ release from stores, and to inadequate Fe bioavailability because of inflammation. In particular, abnormal ferritin concentrations have been 
explained by the chronic low-grade inflammation associated with obesity, the metabolic syndrome and gestational and type 2 diabetes $^{(20-22)}$. Increases in serum ferritin concentrations early in gestation also constitute a risk of gestational diabetes, partly mediated by the maternal fat mass and obesity ${ }^{(21)}$.

The present study also reports interesting relationships between biochemical parameters and specific intestinal bacterial groups in pregnant women. While Bacteroides numbers seemed to have a positive association with plasma biomarkers of lipid metabolism, Staphylococcus numbers seemed to have a negative association, particularly with plasma cholesterol. Cholesterol and other sterols have been shown to stimulate the growth of at least $S$. aureus ${ }^{(23)}$; however, in the present study no correlation was found between cholesterol intake and Staphylococcus numbers, which could explain a link with plasma cholesterol levels. Other mechanisms have been proposed to justify the influence of the intestinal microbiota on lipid metabolism, including the generation of different SCFA and regulation of the host gene expression ${ }^{(6,7,24,25)}$, but the specific relationships found in the present study remain to be elucidated.

Bifidobacterium numbers were positively related to plasma folic acid levels in the whole population, which may be due to the ability of some strains of this genus to synthesise and secrete folates in the human intestinal environment, providing a complementary endogenous source of this vitamin ${ }^{(26)}$. This metabolic trait of Bifidobacterium strains could contribute to improving the nutritional status of the pregnant woman and the fetus.

Enterobacteriaceae/E. coli and Bifidobacterium showed inverse relationships with transferrin, saturation transferrin index and ferritin, as well as with body weight in the whole population. Increases in serum transferrin saturation index, because of a transferrin decrease and ferritin increase, have been associated with a decrease in antibacterial activity of serum against enterobacteria, such as Salmonella enterica, which could contribute to favouring the survival of this bacterial group ${ }^{(27)}$. In fact, infections are one of the conditions that can depress transferrin levels. The possibility that the overgrowth of Enterobacteriaceae in the gut environment might favour their translocation to some extent and cause a similar effect could not be disregarded. By contrast, the administration of inulin to pigs led to increased Lactobacillus and Bifidobacterium numbers and to up-regulating the expression of genes encoding for Fe transporters in the enterocytes, which suggest a connection between these bacterial groups and/or the prebiotic, and improved Fe absorption ${ }^{(28)}$. Therefore, the relative abundance of Bifidobacterium and Enterobacteriaceae may differently influence Fe metabolism and, in turn, exert opposite effects on the nutritional status of pregnant women. Unlikely the present study, a previous report on microbiota of pregnant women did not provide any data on biochemical parameters and their possible associations with the microbiota ${ }^{(10)}$.

In summary, specific bacterial groups are oppositely related to overweight and weight gain during pregnancy, pointing to a beneficial role of Bacteroides and Bifidobacterium in bodyweight regulation. In addition, novel associations between these bacterial groups and beneficial changes in metabolic biomarkers are provided, suggesting a connection between the gut microbiota and the host metabolism. Altogether, these findings open new possibilities for the management of body weight and of the nutritional status of pregnant women through modulation of the intestinal microbiota, which may have consequences on later infant health, and deserve further investigation.

\section{Acknowledgements}

The present study was supported by grants AGL2008-01440/ ALI, Consolider Fun- $C$-Food CSD2007-00063 from the Spanish Ministry of Science and Innovation, AP-124/09 from Consellería de Sanitat (Valencia, Spain) and P06-CTS02341 (Excellence Project PREOBE) from Consejería de Innovación, Ciencia y Empresa de la Junta de Andalucía. (Spain). M. C. C. was recipient of I3P fellowships from CSIC (Spain). A. muciniphila strain $\mathrm{Muc}^{\mathrm{T}}$ (= ATCC BAA$835^{\mathrm{T}}=$ CIP $107961^{\mathrm{T}}$ ) was kindly provided by Molecular Microbial Ecology Group, Laboratory of Microbiology, Department of Agrotechnology and Food Sciences, Wageningen University, Wageningen, The Netherlands.

Y. S. conceived of and coordinated the microbiological study, and drafted the manuscript. A. S. and M. C. C. carried out the microbiological and statistical analyses. C. C. coordinated the clinical follow-up of pregnant women. L. G.-V., M. T. S., J. A. M.-L. and T. A. collected clinical and biochemical data. M. M.-R., R. M. L. and J. F. recruited and followed-up pregnant woman. All authors read, reviewed and approved the final version of the manuscript.

The authors do not have any conflict of interest.

\section{References}

1. Ehrenberg HM, Durnwald CP, Catalano P, et al. (2004) The influence of obesity and diabetes on the risk of Cesarean delivery. Am J Obstet Gynecol 191, 969-974.

2. Chu SY, Callaghan WM, Kim SY, et al. (2007) Maternal obesity and risk of gestational diabetes mellitus. Diabetes Care 30, 2070-2076.

3. Jain NJ, Denk CE, Kruse LK, et al. (2007) Maternal obesity: can pregnancy weight gain modify risk of selected adverse pregnancy outcomes? Am J Perinatol 24, 291-298.

4. Hill JO \& Trowbridge FL (1998) Childhood obesity: future directions and research priorities. Pediatrics 101, 570-574.

5. Jouret B, Ahluwalia N, Cristini C, et al. (2007) Factors associated with overweight in preschool-age children in southwestern France. Am J Clin Nutr 85, 1643-1649.

6. Ley RE, Turnbaugh PJ, Klein S, et al. (2006) Microbial ecology: human gut microbes associated with obesity. Nature 444, 1022-1023.

7. Turnbaugh PJ, Ley RE, Mahowald MA, et al. (2006) An obesity-associated gut microbiome with increased capacity for energy harvest. Nature 444, 1027-1031.

8. Nadal I, Santacruz A, Marcos A, et al. (2009) Shifts in clostridia, bacteroides and immunoglobulin-coating fecal bacteria associated with weight loss in obese adolescents. Int J Obes (Lond) 33, 758-767.

9. Santacruz A, Marcos A, Wärnberg J, et al. (2009) Interplay between weight loss and gut microbiota composition in overweight adolescents. Obesity (Silver Spring) 17, 1906-1915.

10. Collado MC, Laitinen K, Isolauri E, et al. (2008) Distinct composition of gut microbiota during pregnancy in overweight and normal weight women. Am J Clin Nutr 88, 894-899. 
11. Institute of Medicine Subcomittee on Nutritional Status and Weight Gain During Pregnancy (1990) Weight gain and nutrient supplements. In Nutrition During Pregnancy, Part I, pp. 1-233. Washington, DC: National Academy Press.

12. Farran A, Zamora R \& Cervera P (2004) Tablas de Composición de Alimentos del CESNID (CESNID Food Composition Tables), 2nd ed. Barcelona: McGraw-Hill Interamericana.

13. Friedewald WT, Levy RI \& Fredrickson DS (1972) Estimation of the concentration of low-density lipoprotein cholesterol in plasma, without use of the preparative ultracentrifuge. Clin Chem 18, 499-502.

14. Kalliomäki M, Collado MC, Salminen S, et al. (2008) Early differences in faecal microbiota composition in children may predict later weight-gain? Am J Clin Nutr 87, 534-538.

15. Waldram A, Holmes E, Wang Y, et al. (2009) Top-down systems biology modeling of host metabotype-microbiome associations in obese rodents. J Proteome Res 8, 2361-2375.

16. Cani PD, Neyrinck AM, Fava F, et al. (2007) Selective increases of bifidobacteria in gut microflora improve highfat-diet-induced diabetes in mice through a mechanism associated with endotoxaemia. Diabetología 50, 2374-2383.

17. Ray JG, Thompson MD, Vermeulen MJ, et al. (2007) Metabolic syndrome features and risk of neural tube defects. BMC Pregnancy Childbirth 19 (epublication 19 September 2007).

18. Nead KG, Halterman JS, Kaczorowski JM, et al. (2004) Overweight children and adolescents: a risk group for iron deficiency. Pediatrics 114, 104-108.

19. Zimmermann MB, Zeder C, Muthayya S, et al. (2008) Adiposity in women and children from transition countries predicts decreased iron absorption, iron deficiency and a reduced response to iron fortification. Int J Obes (Lond) 32, 1098-1104.
20. Zafon C, Lecube A \& Simó R (2009) Iron in obesity. An ancient micronutrient for a modern disease. Obes Rev (epublication ahead of print version 10 July 2009).

21. Chen X, Scholl TO \& Stein TP (2006) Association of elevated serum ferritin levels and the risk of gestational diabetes mellitus in pregnant women: The Camden Study. Diabetes Care 29, $1077-1082$

22. Lecube A, Hernández C, Pelegrí D, et al. (2008) Factors accounting for high ferritin levels in obesity. Int $J$ Obes (Lond) 32, 1665-1669.

23. Shine WE, Silvany R \& McCulley JP (1993) Relation of cholesterol-stimulated Staphylococcus aureus growth to chronic blepharitis. Invest Ophthalmol Vis Sci 34, 2291-2296.

24. Wolever TMS, Spadafora PJ, Cunnane SC, et al. (1995) Propionate inhibits incorporation of colonic $\left[1,2-{ }^{13} \mathrm{C}\right]$ acetate into plasma lipids in humans. Am J Clin Nutr 61, 1241-1247.

25. Pouteau E, Nguyen $\mathrm{P}$, Ballèvre O, et al. (2003) Production rates and metabolism of short-chain fatty acids in the colon and whole body using stable isotopes. Proc Nutr Soc 62, 87-93.

26. Strozzi GP \& Mogna L (2008) Quantification of folic acid in human feces after administration of Bifidobacterium probiotic strains. J Clin Gastroenterol 42, Suppl. 3, S179-S184.

27. Jolivet-Gougeon A, Loréal O, Ingels A, et al. (2008) Serum transferrin saturation increase is associated with decrease of antibacterial activity of serum in patients with HFE-related genetic hemochromatosis. Am $J$ Gastroenterol 103, 2502-2508.

28. Tako E, Glahn RP, Welch RM, et al. (2008) Dietary inulin affects the expression of intestinal enterocyte iron transporters, receptors and storage protein and alters the microbiota in the pig intestine. Br J Nutr 99, 472-480. 